Яшина Мария Николаевна

кандидат социологических наук, доцент, Санкт-Петербургский

государственный университет

\section{РЕПЕТИТОРСТВО В СИСТЕМЕ ПОДГОТОВКИ ШКОЛЬНИКОВ В САНКТ-ПЕТЕРБУРГЕ [1]}

\section{Аннотация}

Репетиторство как форма поддержки образования существует довольно давно. С активным внедрением ЕГЭ, требованием к текущему уровню усвоения материалов школьниками, степень вовлеченности семей в этот вид дополнительного образования возрастает от одной ступени обучения к другой. При этом роль репетиторов становится предметом обсуждения в профессиональной среде. В статье анализируются данные Мониторинга экономики образования за период с 2010 по 2012 г. В целях выявления видов репетиторства в системе подготовки школьников сделана подвыборка опрошенных в школах Санкт-Петербурга $(\mathrm{N}=$ 301 чел.). Проанализирована связь между уровнем обучения и степенью вовлеченности учеников в занятия с репетиторами. Установлены мотивы запроса со стороны родителей к репетиторам в зависимости от причин выбора учебного заведения.

Ключевые слова:

репетиторство, уровни образования, типы школ, учащиеся, цели найма репетиторов, родители.
Yashina Maria Nikolaevna

$\mathrm{PhD}$ in Sociology, Associate Professor, St. Petersburg State University

\section{TUTORING IN THE SCHOOL TRAINING SYSTEM IN ST. PETERSBURG [1]}

Summary:

Tutoring as a form of educational support has existed for quite a long time. With the active implementation of the Unified State Exam, the requirement for the current level of learning of materials by schoolchildren, the degree of involvement of families in this type of additional education increases from one stage of education to another. At the same time, the role of tutors becomes a subject of discussion in the professional environment. The study analyzes the data of the Education Economy Monitoring for the period from 2010 to 2012. In order to identify types of tutoring in the school training system, a sub-sample of respondents in St. Petersburg schools was made $(N=$ 301 people). The relationship between the level of education and the degree of involvement of pupils in classes with tutors was analyzed. The motives of the request from parents to tutors are established, depending on the reasons for choosing an educational institution.

Keywords: tutoring, education levels, schools types, students, goals for hiring tutors, parents.

В последние годы репетиторство стало активно встраиваться в учебный процесс. Этот элемент дополнительного образования имеет сторонников и противников в среде родителей, учителей и научного сообщества. Для одних родителей репетиторство является панацеей, и без помощи специалистов они не мыслят обучение ребенка. Другие видят в нем возможность школы уйти от обязанностей, переложив их на плечи родителей. По результатам опроса педагогов средних образовательных учреждений Санкт-Петербурга, проведенного сотрудниками Санкт-Петербургской академии постдипломного педагогического образования, «по мнению почти половины учителей, сегодняшняя школа находится в такой ситуации, когда при всем своем старании она не может обойтись без помощи этой дополнительной образовательной фрормы» [2, с. 93]. В научном сообществе проблематика репетиторства активно обсуждается последнее десятилетие. В педагогическом дискурсе рассматривается результативность данной формы [3]. Она расценивается и как вид экономической практики. Социологический анализ обширно представлен в описании результатов мониторинга экономики образования [4].

Для изучения целей найма репетиторов на примере Санкт-Петербурга проведен вторичный анализ результатов опроса родителей школьников на основе реализуемого в НИУ ВШЭ мониторинга экономики образования, материалы которого депонированы в Едином архиве экономических и социологических данных (ЕАЭСД). Сбор информации осуществлялся АНО «Левадацентр». Доступ к итогам опросов до 2012 г. включительно предоставлен ЕАЭСД. В каждой школе, попавшей в выборочную стратифицированную совокупность, опрашивались по 30 родителей учащихся 1-4-х, 5-7-х и 8-11-х классов. Анкета отдавалась родителям на самозаполнение.

Для оценки ситуации в Санкт-Петербурге сделана подвыборка по опросам 2010-2012 гг. За указанный период опрошено 414 родителей. Для вторичного анализа отбирались учебные заведения, которые попадали в выборку впервые за указанные годы. В итоге исследование проводилось по данным опроса 301 родителя учащихся из государственных (8) и частных (2) школ. Основными целями найма репетиторов являются подготовка к ЕГЭ/ОГЭ, помощь в изучении недостаточно освоенного предмета, а также углубление знаний (таблица 1). Не занимались с репетиторами за рассматриваемый промежуток времени 65 \% респондентов. 
Таблица 1 - Цели найма репетиторов в Санкт-Петербурге, \%

\begin{tabular}{|l|c|}
\hline \multicolumn{1}{|c|}{ Цель найма } & Доля \\
\hline Подтянуть знания по предмету & 12,1 \\
\hline Для подготовки к сдаче экзамена, в том числе ЕГЭ & 11,1 \\
\hline Для углубленного изучения какого-либо предмета & 10,8 \\
\hline Для общего развития & 3,4 \\
\hline Для подготовки к поступлению в вуз & 3,7 \\
\hline Для подготовки к поступлению в училище, техникум & 0,7 \\
\hline Другое (что именно?) & 2,7 \\
\hline Не занимается с репетитором в этом учебном году & $\mathbf{6 5 , 0}$ \\
\hline
\end{tabular}

Несмотря на то что образовательные заведения принадлежат к разным типам (лицей/гимназия, школа с углубленным изучением предметов, образовательная школа) и фрормам собственности (государственные/негосударственные) статистически значимой разницы между целями найма репетиторов по основным трем показателям нет.

Различия присутствуют в потребностях в дополнительной помощи на разных уровнях получаемого образования. На этот фрактор обратила внимание в 2014 г. А.Я. Бурдяк при анализе данных, полученных при опросе 1505 родителей учащихся 1-11-х классов Москвы. Она выявила, что услугами репетиторов пользуются «13 \% учеников 1-4-х классов, 28 \% учеников 5-7-х классов, 54 \% школьников 8-9-х классов и 68 \% учеников 10-11-х классов» [5, с. 111]. В Петербурге по мере перехода с одной ступени образования на другую также увеличивается количество семей, прибегающих к услугам репетиторов, - с 15 \% в начальной школе до 60 \% в старшей. В связи с разными образовательными задачами на каждом этапе существенно изменяется и структура потребностей в репетиторах.

В начальной и средней школе, когда главное - это сам процесс, а не итоговый результат, наиболее значимыми мотивами выступают углубление знаний по предмету и помощь в освоении материала. Ситуация с целями найма репетиторов у старшеклассников, в связи с особенностями ЕГЭ как единственного в настоящее время способа оценки знаний школьников и из-за этого слишком высоких ставок в отношении него, отличается от всех других уровней обучения. Поэтому для старшей школы ведущим становится мотив подготовки к выпускным экзаменам для результативной сдачи ЕГЭ, все остальное уходит на второй план (таблица 2). Для начальной и средней школы статистические различия наблюдаются по целям «подтянуться по предмету» и «углубленное изучение предмета». На первых ступенях школьного образования родители хотят углублять знания по предметам, а чем ближе к окончанию и экзаменам задача заключается в восполнении пробелов. Статистических различий между остальными целями найма не наблюдается. Сами репетиторы также указывают на эти три ведущих запроса со стороны родителей, хотя и предлагают более обширный спектр услуг: повышение интереса к учебе, развитие личностных качеств ученика, помощь в выполнении домашних заданий, подготовки к контрольным [6].

\section{Таблица 2 - Цели найма репетиторов в зависимости от уровня образования} в Санкт-Петербурге, \%

\begin{tabular}{|c|c|c|c|c|}
\hline Цель найма & $\begin{array}{c}\text { Начальная школа } \\
\text { (1-4-й классы) }\end{array}$ & $\begin{array}{l}\text { Средняя школа } \\
\text { (5-7-й классы) }\end{array}$ & $\begin{array}{l}\text { Средняя школа } \\
\text { (8-9-й классы) }\end{array}$ & $\begin{array}{c}\text { Старшая школа } \\
\text { (10-11-й классы) }\end{array}$ \\
\hline $\begin{array}{l}\text { Подтянуть знания } \\
\text { по предмету }\end{array}$ & 6,7 & 10,1 & 18,9 & 6,8 \\
\hline $\begin{array}{l}\text { Для подготовки к сдаче } \\
\text { экзамена, в том числе } \\
\text { ЕГЭ/ОГЭ }\end{array}$ & 0,0 & 0,0 & 11,6 & 30,1 \\
\hline $\begin{array}{l}\text { Для углубленного изучения } \\
\text { какого-либо предмета }\end{array}$ & 8,0 & 17,7 & 6,3 & 8,2 \\
\hline Для общего развития & 2,7 & 3,8 & 4,2 & 1,4 \\
\hline $\begin{array}{l}\text { Для подготовки к поступле- } \\
\text { нию в вуз }\end{array}$ & 0,0 & 0,0 & 2,2 & 12,3 \\
\hline $\begin{array}{l}\text { Для подготовки к поступле- } \\
\text { нию в училище, техникум }\end{array}$ & 0,0 & 0,0 & 2,1 & 0,0 \\
\hline Другое (что именно?) & 1,3 & 1,3 & 4,2 & 2,7 \\
\hline $\begin{array}{l}\text { Не занимается с репетито- } \\
\text { ром в этом учебном году }\end{array}$ & 85,3 & 67,1 & 50,0 & 38,4 \\
\hline
\end{tabular}

Репетиторство в процессе учебы выполняет в первую очередь компенсаторно-развивающую функцию. Этим можно объяснить отсутствие статистически значимой разницы в оценках у тех детей, которые пользуются услугами репетиторов, и тех, кто к ним не прибегает. У «слабых» учеников результаты дополнительных занятий не отражаются на текущих отметках, измеряющих 
усвоенность темы здесь и сейчас, из-за необходимости подтягивать ранее изученный материал, а у «сильных» школьников дополнительный материал соответствует заданиям повышенной сложности, которые не являются основными при оценке текущих знаний.

Помимо ступени обучения, на цели найма репетитора оказывают влияние и особенности выбора и способа поступления в учебное заведение. Статистические значимые связи дают следующие переменные: конкурсные испытания при поступлении в школу, близость школы к дому, квалификация преподавателей, состав обучаемых, подготовка в вуз и специализация заведения. В свою очередь, перечисленные причины служат индикаторами территориального и институционального барьеров в получении качественного образования [7] (таблица 3).

\section{Таблица 3 - Связь причины выбора школы и занятий с репетиторами} в Санкт-Петербурге, \%

\begin{tabular}{|l|c|c|}
\hline \multicolumn{1}{|c|}{ Причина } & \multicolumn{2}{c|}{ Занимается с репетитором в этом учебном году } \\
\cline { 2 - 3 } & да & нет \\
\hline $\begin{array}{l}\text { Прохождение собеседования или вступительных испыта- } \\
\text { ний при поступлении в школу }\end{array}$ & 53,7 & 35,8 \\
\hline Школа расположена близко к дому & 37,0 & 50,8 \\
\hline Квалифицированные преподаватели & 61,1 & 48,2 \\
\hline Хороший контингент учащихся & 32,4 & 18,1 \\
\hline Хорошая подготовка для поступления в вуз & 25,0 & 15,5 \\
\hline $\begin{array}{l}\text { Специализированная школа (с углубленным изучением } \\
\text { предметов) }\end{array}$ & 23,1 & 38,3 \\
\hline
\end{tabular}

Потребность в тех или иных услугах репетиторов зависит от выбора семьей школы. Если основные причины связаны с территориальной близостью, в этом случае родители беспокоятся за финальный результат и целью дополнительных занятий являются подготовка к экзаменам и восполнение пробелов. Выбор более качественной школы, в которой наблюдаются высокая квалификация учителей и подходящий контингент учащихся, а также подготовка к выпускным экзаменам вынуждают семьи обращаться за помощью к репетиторам для восполнения пробелов или углубления знаний, которые, как правило, более востребованы в «сильных» школах.

Учителя, в свою очередь, «не только одобряют репетиторство, но в случае, если бы у их детей (внуков) возникли проблемы с учебой, то 77,1 \% из них обратились бы за помощью к репетитору. При этом 17,3 \% сказали, что их дети (внуки) занимаются с репетитором в настоящее время, а еще 23,0 \% отметили, что занятия с репетитором у их детей (внуков) были раньше» [8, с. 91].

Проанализированные данные позволяют говорить о наибольшей востребованности репетиторства на старших ступенях обучения в связи с подготовкой к экзаменам. Этот злободневный вопрос значим для школьника и его семьи только в критических точках.

Главными элементами в репетиторстве как процессе являются два вектора - поддержка при неусвоении материала и углубление знаний. По нашему мнению, они представляют собой разные стратегии формирования и индивидуализации образовательного маршрута ребенка со стороны семьи, а также преодоления или снижения барьеров на пути к получению качественного образования. Говоря о репетиторстве и его целях, нельзя не учитывать отношение школы к этому феномену. Позитивная оценка педагогов, выражающаяся в том, что «плюсы от репетиторства для учителей и соответственно школы значительно превалируют над возможными негативными эффректами, многие из которых учителя оценивают как незначительные» [9, с. 95], усиливает проблематику эфффективности работы образовательного учреждения по обучению ребенка.

\section{Ссылки и примечания:}

1. Статья подготовлена при финансовой поддержке РФФИ в рамках научного проекта № 19-011-00947 А

2. Матюшкина М.Д., Белоусов К.Ю. Репетиторство в оценках педагогов школ Санкт-Петербурга // Наука и школа. 2019. № 5. C. 88-97. https://doi.org/10.31862/1819-463X-2019-5-88-97.

3. Матюшкина М.Д. Эффективность школы и ее критерии в современных условиях распространения репетиторства и доступности интернета // Непрерывное образование: XXI век. 2019. № 1 (25). С. 53-64 ; Нуриева Л.М., Киселев С.Г. О бедном репетиторе замолвите слово (еще раз об эффеективности репетиторства для подготовки к ЕГЭ) // Образование и наука. 2018. № 20 (8). С. 148-163. https://doi.org/10.17853/1994-5639-2018-8-148-163.

4. Рощина Я.М., Филиппова Т.Н. Школьное образование глазами родителей // Народное образование. 2013. № 2. С. 74-82.

5. Бурдяк А.Я. Дополнительные занятия по школьным предметам: мотивация и распространенность // Мониторинг общественного мнения: экономические и социальные перемены. 2015. № 2 (125). С. 96-112.

6. Шипкова Е.Н. Репетиторство как проблема педагогической науки и практики // Ярославский педагогический вестник. 2018. № 2. C. 39-46. https://doi.org/10.24411/1813-145X-2018-20005.

7. Доступность качественного общего образования в России: возможности и ограничения / Д.Л. Константиновский, В.С. Вахштайн, Д.Ю. Куракин, Я.М. Рощина // Вопросы образования. 2006. № 2. С. 186-202.

8. Матюшкина М.Д., Белоусов К.Ю. Указ. соч. С. 91. 
9. Там же. С. 95.

\section{References:}

Burdyak, AYa 2015, 'Additional Classes in School Subjects: Motivation and Prevalence', Monitoring obshhestvennogo mnenija: jekonomicheskie i social'nye peremeny, no. 2 (125), pp. 96-112, (in Russian).

Konstantinovsky, DL, Wachstein, VS, Kurakin, DYu \& Roschina, YaM 2006, 'The Availability of Quality General Education in Russia: Opportunities and Limitations', Voprosy obrazovanija, no. 2, pp. 186-202, (in Russian).

Matyushkina, MD \& Belousov, KYu 2019, 'Tutoring in the Assessments of Teachers in Schools of Saint-Petersburg', Nauka i schola, no. 5, pp. 88-97, https://doi.org/10.31862/1819-463X-2019-5-88-97, (in Russian).

Matyushkina, MD 2019, 'School Effectiveness and Its Criteria in the Current Conditions of the Spread of Tutoring and Internet Access', Neprerivnoe obrazovanie: XXI vek, no. 1 (25), pp. 53-64, (in Russian).

Nurieva, LM \& Kiselev, SG 2018, 'Let's Hear It Once More for the Unsung Coach: on the Efficiency of Coaching for the Unified State Exam', Obrazovanie i nauka, no. 20 (8), pp. 148-163, https://doi.org/10.17853/1994-5639-2018-8-148-163, (in Russian).

Roschina, YaM \& Filippova, TN 2013, 'School Education Through the Eyes of Parents', Narodnoe obrazovanie, no. 2, pp. 74-82, (in Russian).

Shipkova, EN 2018, 'Tutoring as a Problem of Pedagogical Science and Practice', Jaroslavskij pedagogicheskij vestnik, no. 2, pp. 39-46, https://doi.org/10.24411/1813-145X-2018-20005, (in Russian).

Редактор: Тюлюкова Мария Олеговна Переводчик: Ездина София Александровна 